\title{
Transport Optimization of the Reverse Logistics System During Territories Sustainable Development
}

\author{
Irina Makarova, Denis Kuznetsov, Polina Buyvol*, Ksenia Shubenkova \\ Kazan Federal University, Naberezhnye Chelny, Russian Federation \\ ${ }^{*}$ Corresponding author. Email: skyeyes@mail.ru
}

\begin{abstract}
The observed growth in the consumption level and the limited resources reserves exhaustion contradicts to the principles of sustainable development. The latter requires re-use of end-of-life products as part of the transition to a circular economy. This implies to develop methods and tools for building closed-loop chains in logistics systems and improving the movement of reverse flows. A simulation model was developed for both the delivery of goods to sale points and removal from them of accumulated products that were in use and handed over by consumers for further processing. As a result of a computer experiment the model allows to make well-founded decisions on the selection of vehicle fleet. Thus, we solve the third stage problem of organizing performance of a closed-loop supply chain - transport logistics' optimization. Products transportation and storage costs are considered as the target functionality. Variable parameters are vehicles' number in the fleet, lots size and driving intervals. Additional restrictions are minimum allowable level of vehicle loading and minimum required level of goods assortment in the store. The performed approbation on real data has shown the effectiveness of the proposed approach.
\end{abstract}

Keywords: Carrying capacity, Delivery frequency, Reverse logistic, Simulation, Vehicle fleet.

\section{INTRODUCTION}

Now the usage scale of natural resources is so great that it threatens to exceed their existing reserves. For example, in the future, global consumption of clothing and footwear is expected to increase by $62 \%$ to 103 million in 2035 [1]. Along with this, the amount of garbage is also growing. So, in Russia, the volume of solid waste is 26 billion tons, with an annual increase of this indicator by 530 million tons. At the same time, the percentage of solid waste recycling in most countries is very low. According to the Ellen MacArthur Foundation, less than $2 \%$ of textiles made from clothes are currently recycled into new clothes, representing a missed opportunity of over $\$ 150$ billion annually and high utilization and incineration costs. Thus, there is a significant reduction in land plots for agricultural needs and an increase in waste disposal costs. In addition, the incineration or burial of solid waste causes serious harm to the environment.

All this testifies to the need for the earliest possible implementation of the sustainable development principles. In particular, this requires a transition to a circular economy that implements the "take, make, reuse" principle [2]. This approach allows to raise environmental efficiency to a new level, while preventing the loss of significant amounts of resources during disposal of end-of-life products at landfills.

At the same time, in order to obtain the effects of the principle of "take, make, reuse" it is necessary to change the paradigm in the organization of logistics systems, which led to the emergence of "reverse logistics" concept, and the development of methods and tools for building closed-loop chains in logistics systems and improving the movement of reverse flows.

\section{METHODS OF REVERSE LOGISTIC ORGANISATION: LITERATURE REVIEW}

Reverse logistics is defined by the European Reverse Logistics Working Group as "the process of planning, implementing and controlling the reverse flows of raw materials, inventories, packaging and finished goods from the point of production, distribution or use to the point of recovery or proper disposal" [3]. In fact, it directly includes logistics management and activities to reduce and eliminate the loss of containers and products. This implies a reverse distribution - the movement of goods and information in a direction opposite to that in which traditional logistics activities take place. To 
organize the effective functioning of this process, methods of planning the volumes of reverse logistics flows, the territorial distribution of the reverse logistics system's nodes, as well as the organization of transport logistics in closed-loop supply chains are distinguished.

\subsection{Planning and creation of reverse logistics flows volumes}

The primary task when organizing a reverse logistics system is to create a reverse flow in the supply chain. To do this, manufacturers must develop and implement a take-back program. Thus, the world-renowned clothing brand $H \& M$ pursues a targeted policy in the field of environmental management. Since 2015, one such program is the recycling and reusing of textiles, which is called Recycling Revolution. All over the world, H\&M stores offer their customers to recycle old and unwanted clothing. To increase interest in the problem of proper environmental management, the company issues discount coupons to customers for each package of textiles [4].

Consumers are reluctant to waste time returning unwanted and old things, which are much easier and faster to throw in a landfill, therefore information technology is actively used to popularize the principles of a circular economy. For example, the free reGAIN app helps customers find the closest collection point of over 25,000 UK collection points, receive a shipping receipt and discount coupons valid for 10 days [5].

Due to the variability in the quality of returned used products, refurbishes are required to conduct $100 \%$ inspection of these products to assess their quality and suitability for recycling. Quick sorting is often made possible by the installation of simple electronic devices (in particular RFID tags) in new products that record basic usage data and provide information on the product recoverability without the need to disassemble it. After analyzing and compiling a simple analytical expression, the authors in [6] prove that sorting before disassembly is economically attractive when the costs of sorting, disposal and transportation are low, disassembly costs are high, sorting accuracy is high, and average quality (reusability) returned used products is low.

In [7] authors proposed a new mixed integer programming approach to maximize the benefit from the disassembly process, which is the difference between the income generated from the resale of remanufactured items and the costs associated with performing disassembly tasks. Several numerical tests using the wellknown CPLEX solver have proven that this new model can find the optimal disassemble schedule for most test cases in a reasonable computation time. After analyzing the sensitivity to disassembly, set-up time, and purchase costs, the authors conclude that if the ratio between disassembly margin and the cost of purchasing a component is equal to or greater than 10 , it is better to order the component than receive it by disassembling an end-of-life product.

Analysis of logistic processes during the transition to a circular economy makes it possible to name such different sources of uncertainty in reverse logistic flows, such as quality, price, time and quantity of returned components [8]. Article [9] provides a comprehensive review of research published in various scientific journals on the logistics networks' optimization. They concluded that current work usually does not consider the factors affecting the characteristics of product returned in their entirety, and in order to predict the reverse logistics system's parameters several methods and methodologies are used that are adopted for predicting the direct supply chain. When solving the problem of determining the dynamic batch size, manufactured and remanufactured products do not differ, it is assumed that the sums of demand for new and remanufactured products are known for all periods of the planning horizon, and the fact that remanufactured products may not be of sufficient quality for secondary use is not taken into account.

The stochastic nature of the reverse logistics system's parameters distinguishes the methods applied to it from the approaches used in the construction and optimization of traditional logistics [10-12].

\subsection{Territorial location and value design of the reverse logistics system's nodes}

Network design and sizing is one of the strategic and complex decisions to be made in the return supply chain after assessing flow volumes. Efficient and proper design of the logistics network results in the economic benefits from the use of returned products, increased customer satisfaction and market share, reduced costs [13].

In article [14], multi-purpose planning is used to create a recycling network. The objective is to minimize operating costs and maximize customer service. Solution variables include the configuration of the nodes in the recirculation network and the traffic volume between the nodes in the network. Customer satisfaction and balancing the inflow and outflow of nodes are the constraints. Multipurpose programming is transformed into single-purpose programming using the $\varepsilon$-constraint. The model minimizes costs and maximizes customer service levels while meeting their needs. The application of this model contributes to the efficient planning of the logistics hub and the creation of a scheme for optimizing reverse logistics, taking into account the reduction of costs and an increase in the level of customer service.

In [15], the authors explored the joint location and inventory problem to optimize enterprise location and inventory management challenges for a new business program launched by a leading e-commerce company in China. It should be noted that this problem belongs to the 
class of NP-hard, so they formulated it as a mixed-integer nonlinear programming model and to solve it efficiently developed a new heuristic approach based on differential evolution.

In many works, the design of the reverse supply network has been planned to reduce costs and improve customer service without considering the environmental impact. Therefore, the ecological aspect requires further elaboration. Thus, in the article [16] the authors address the problem of designing a reverse logistics network associated with carbon emissions. The problem is formulated as a dual-purpose, mixed-integer and nonlinear programming model for various operating technologies and transport modes, which considers the trade-off between profit and $\mathrm{CO} 2$ emissions when designing a reverse logistics network. The analysis of the results shows that the design decisions for the optimal cost-effective solution and the optimal solution for carbon emissions are different. This study lays the foundation for work on the design of a carbon-based reverse supply network. Due to the complexity of the problem, only one transport mode was considered for the reverse logistics network, but two or more modes of transport can be selected to expand the study.

Article [17] presents an integrated approach to designing a reverse logistics network by minimizing carbon emissions and transport distances between different candidate centers, while considering several systemic and operational issues of a hybrid production and recovery system operating in a reverse logistics network. An attempt is made to integrate various aspects of sustainable development inherent in the philosophy of sustainable production, a scheme of a reverse logistics network based on a carbon footprint is presented, which consists of customer, collection, disassembly sites.

In [18], the authors also took into account the carbon footprint when creating a model for optimizing the reverse logistics network for waste recycling. A solution method based on a multipurpose gray wolf optimization algorithm was proposed, which solves the problems of low convergence rate and many parameters that were difficult to apply.

The model presented in [19] is designed to find optimal solutions to meet demand and revenue needs by focusing on strategic locations for collection centers, recycling centers, remanufacturing plants and transportation options, while achieving sustainable development goals. The model is converted to a multipurpose programming model. All objective functions are evaluated using the best worst method, analytic hierarchy process, and fuzzy analytic hierarchy process in order to obtain weights for integration into the model a fuzzy linear programming. That ultimately yields three separate results. The applied model is original and unique for solving multipurpose problems in an uncertain environment and seeks to find a balance between economic and environmental goals. The study provides a framework for further encompassing uncertainty about the quantity and quality of returned products.

As noted in [20], future research should focus on building multipurpose and non-linear models, addressing carbon caps within a rigorous environmental policy, addressing additional uncertainties, and adopting better methods for solving.

\subsection{Organization of transport logistics in closed-loop supply chains}

At the third stage of managing the reverse logistics system, the problem of optimizing delivery routes and vehicle fleet used is solved. The vehicle routing problem (VRP) is about finding optimal routes for a fixed vehicle fleet so that they can meet customers' needs while traveling those routes. This problem and its numerous extensions are one of the most important and most relevance problems of transportation and logistics [21]. However, numerous studies on vehicle routing problem with cross-docking (VRPCD) have considered only forward flow, not reverse flow. The study [22], given the ability to minimize downstream distribution costs, includes a reverse logistics scheme in the VRPCD network. The authors, in order to minimize the operating and transport costs of vehicles, proposed a VRPRCD mathematical model for a four-tier supply chain network, which includes suppliers, cross-dock, customers and retail outlets.

Return traffic is an increasingly interesting option for solving real-world transport problems, and it can provide significant reductions in overall routing costs and improve traffic sustainability. The vehicle routing problem with backhauls (VRPB) enables the integration of inbound and outbound routes, which is an effective strategy to reduce routing costs and environmental and social impact of transport. Future directions for VRPB to expand green logistics are: developing sustainable VRPB models that take into account multipurpose functions with economic, environmental and social concerns; exploring additional and broader aspects in collaborative VRPBs such as contracts and profit sharing among participants; exploring the potential of different return run strategies when possible, such as trade-offs between priority and mixed transit, and between additional and restrictive transit runs; development of integrated models combining VRPB and reverse logistics, covering deliveries and pickup from customers and pickups from suppliers; developing effective models to incorporate uncertainty and dynamism into VRPB models and measuring decisions' reliability [23].

The work [24] proposes a mathematical model, which is the first for the simultaneous determination of the number and routes of CLSC-PRP. Since the problem is known to be NP-hard in terms of computational 
complexity, a decomposition heuristic based on simulated annealing has been developed to solve largescale CLSC-PRP instances.

Study [25] attempted to describe the transportation system for industrial waste in the automotive industry by proposing a limited routing model for a heterogeneous vehicle fleet. A hybrid multicriteria decision-making approach has been proposed. Numerical examples have proved that the model, taking into account a heterogeneous transport fleet and separate waste collection, is a safe solution to reduce logistics costs in the presence of transportation risk criteria.

Study [21] explores the issue of routing and scheduling of green vehicles with a heterogeneous fleet, including reverse logistics in the form of collecting returned goods together with weighted costs at an early and late date, in order to find a trade-off between operating and environmental costs and to minimize them simultaneously. In this regard, a mixed integer nonlinear programming model is proposed.

The study [26] improves models for calculating carbon emissions for rolad transport, taking into account a number of regulatory-compliant constraints, such as driving time limits. An example of transportation route planning from a logistics hub to a logistics demand hub in China is used to derive a road freight transportation route strategy (RFTRS). The results show that the optimized RFTRS with the lowest carbon emissions does not necessarily meet the driving time limits of local traffic regulations, nor does it require minimum transportation costs; it should not include too many goods movements at intermediate nodes or plan the nodes of logistics functions in reverse order; low carbon emissions and regulatory requirements for RFTRS are achieved simultaneously in the shortest expressway scenario. The RFTRS optimization process means that high quality roads, such as highways, offer certain benefits, including flexibility in calculation procedures to comply with local traffic and safety regulations, and the ability to quickly and easily find optimal carbon reduction solutions and planning route. According to the authors, the ability to manage a RFTRS in an optimized and sustainable way, taking into account not only low transport costs, but also reduced carbon emissions and traffic regulation requirements, is a clear competitiveness of logistics companies in the future.

\section{RESULTS AND DISCUSSION}

It is rather difficult to accurately describe the reverse logistics system using only analytical methods due to the large number of elements, parameters and factors that affect it. Moreover, external factors, input processes' parameters and system's characteristics themselves are of a probabilistic nature. Therefore, the results of predicting and optimizing system behavior using analytical functions may be completely unreliable. In contrast to them, simulation models allow to take into account the stochasticity of both the reverse logistic flows themselves and other parameters (vehicle fleet reliability, deviations in travel and loading / unloading time). Also, on the simulation model, we can "play" several feasible solutions. Therefore, simulation was chosen as a method for determining the optimal number of vehicle fleets for organizing a two-level reverse logistics system.

We investigate at a specific example. The task is to optimize the forward and reverse logistics processes in the clothing distribution network, numbering 14 stores in the Russian Federation, which are the official dealers of the factory located in Spain. The plant produces and delivers goods by air to the central warehouse in Moscow at the time when there are less than $\mathrm{N}$ units of goods. Orders for delivery from stores are sent to the central warehouse in the form of an order. Old and unnecessary clothes that were handed over by consumers to the store are removed on road transport that delivers goods to stores.

The AnyLogic package was chosen as a modeling environment due to the fact that its modeling system is based on an object-oriented concept, which allows developers to organize and represent the structure of complex systems in a very simple and natural way. In addition, it allows for multiple modeling approaches. For example, a discrete approach was used to model the transportation process. An agent-based approach was also applied. The agents are "Main" (includes a map with a production site, a central warehouse and stores linked to a GIS, Fig. 1), "Central warehouse" (its block diagram

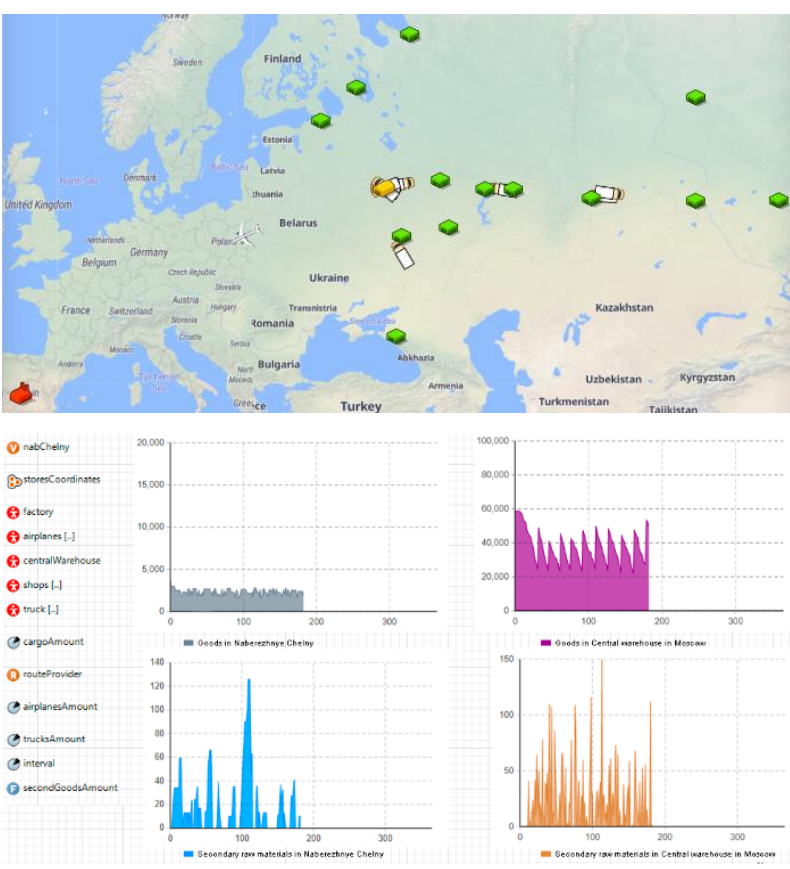

Figure 1 «Main» agent.

includes the assignment of a vehicle to an incoming order, loading, delivery of goods, unloading, loading of end-of-life goods and return of the vehicle to the central 
warehouse), "Truck", "Airplane", "Shop", (represented by state diagrams, Fig. 2 and 3), "Factory", "Order ".

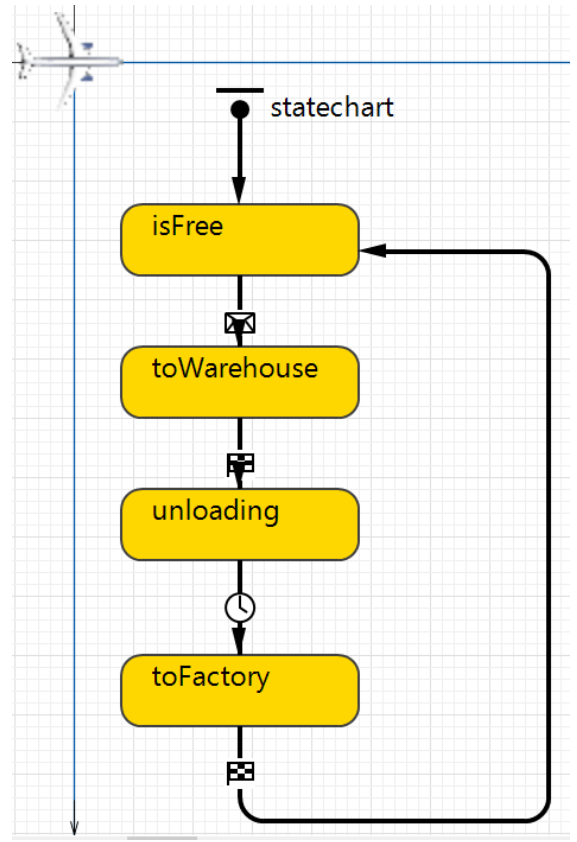

Figure 2 State diagram of the "Airplane" agent.

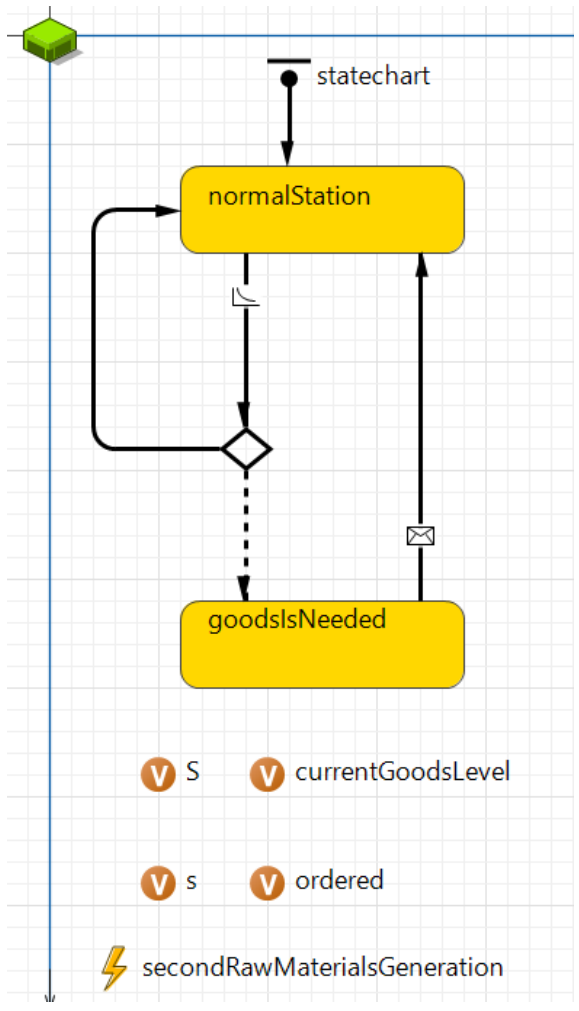

Figure 3 State diagram of the "Shop" agent.

As a result of a computer experiment the model allows to make well-founded decisions on the selection of vehicle fleet. Thus, we solve the third stage problem of organizing performance of a closed-loop supply chain - transport logistics' optimization. Products transportation and storage costs are considered as the target functionality.
Variable parameters are vehicles' number in the fleet, lots size and driving intervals. Additional restrictions are minimum allowable level of vehicle loading and minimum required level of goods assortment in the store.

We carried out an optimization experiment on the model at the given values of demand and the intensity of clothes delivery by the population for recycling. The minimum allowable truck load is $85 \%$. Parameter properties: (1) Number of trucks: minimum number - 1 , maximum - 20, variation step -1 ; (2) Lot size: minimum amount of cargo 100, maximum - 1500, step - 100; (3) Delivery interval minimum time in days - 1 , maximum 30 , step - 1 .

It was found that 10 trucks need to be available to keep the logistics system running smoothly. In order to ensure a given level of goods assortment, it is necessary to deliver 800 units of goods from the central warehouse in Moscow with an interval of 16.6 days.

\section{CONCLUSION}

In modern conditions of growing consumption and a limited value of natural resources, the transition to a circular economy becomes relevant, when the very principle of building supply chains is changing. The use of the principle "products" reuse" makes it possible to reduce the environmental load in terms of the amount of resources used, as well as waste disposal and utilization. All this makes it possible to develop the application the concept of territories sustainable development. The stochastic nature of the reverse logistics system's parameters does not allow using the methods used in the designing of a traditional direct logistics system. A simulation model was developed for both the delivery of goods to sale points and removal from them of accumulated products that were in use and handed over by consumers for further processing. The performed approbation on real data has shown the effectiveness of the proposed approach.

\section{AUTHORS' CONTRIBUTIONS}

Conceptualization - I.M., methodology - I.M., P.B. and K.S., investigation - P.B., D.K. and K.S., modelling - D.K., writing - P.B. and D.K.

\section{ACKNOWLEDGMENTS}

The reported study was funded by RFBR, project number 19-29-06008 $\backslash 20$.

\section{REFERENCES}

[1] Global Fashion Agenda. A call to action for a circular fashion system. Policy brief, https://www.globalfashionagenda.com/wpcontent/uploads/2017/04/GFA17_Call-toaction_Poluc-brief_FINAL_9May.pdf, 2017. 
[2] I. Makarova et al., The Role of Reverse Logistics in the Transition to a Circular Economy: Case Study of Automotive Spare Parts Logistics, in: FME TRANSACTIONS, 49(1) (2021) pp. 173-185.

[3] D. S. Rogers, R. S. Tibben-Lembke, Going backwards: reverse logistics trends and practices, in: Reverse Logistics Executive Council, Reno, 1999.

[4] H\&M, Official site. Recycling Revolution. https://hmfoundation.com/recycling-revolution/.

[5] reGAIN app, Official site. https://regain-app.com/.

[6] C. Zikopoulos, G. Tagaras, On the attractiveness of sorting before disassembly in remanufacturing, in: IIE Transactions, 40(3) (2008) pp. 313-323.

[7] I. Slama et al., New mixed integer approach to solve a multi-level capacitated disassembly lot-sizing problem with defective items and backlogging, in: Jour of Manuf Systems, 56 (2020) pp. 50-57.

[8] P. Buyvol et al., The Service Center Simulation Model as a Part of a Reverse Logistics System, in: Proceedings - International Conference on Developments in eSystems Engineering, DeSE, 9450789 (2020) pp. 105-110.

[9] H. E. Hachimi et al., The optimization of Reverse Logistics activities: A Literature Review and Future Directions, in: 2018 IEEE International Conference on Technology Management, Operations and Decisions, 2018, pp. 18-24.

[10] V. Shepelev et al., Optimization of the operating parameters of transport and warehouse complexes, in: Transportation Research Procedia, 30 (2018) pp. 236-244.

[11] K. Vakulenko et al., Designing optimal public bus route networks in a suburban area, in: Transportation Research Procedia, 39 (2019) pp. 554-564.

[12] A. Galkin et al., Last-mile delivery for consumer driven logistics, in: Transportation Research Procedia, 39 (2019) pp. 74-83.

[13] E. Kilic, S. S. Ali, G. W. Weber, R. Dubey, A value adding approach to reliability under preventive maintenance costs and its applications, in: Optimization, 63(12) (2014) pp. 1805-1816.

[14] B. Wang, H. Li, Optimization of Electronic Waste Recycling Network Designing, in: 2020 5th Int Conf on Electromechanical Control Techn and Transp, Nanchang, China, 2020, pp. 368-371.

[15] H. Guo et al., Location-inventory decisions for closed-loop supply chain management in the presence of the secondary market, in: Ann Oper Res, 291 (2020) pp. 361-386.
[16] Q. Yuchi et al., A bi-objective reverse logistics network design under the emission trading scheme, in: IEEE Access, 7 (2019) pp. 105072-105085.

[17] T. Aljuneidi, A.A. Bulgak, Carbon footprint for designing reverse logistics network with hybrid manufacturing-remanufacturing systems, in: Jnl Remanufactur, 10 (2020) pp. 107-126.

[18] X. Jiang et al., Design of reverse logistics network for remanufacturing waste machine tools based on multi-objective gray wolf optimization algorithm, in: IEEE Access, 8 (2020) pp. 141046-141056.

[19] S.S. Ali et al., Reverse logistics optimization of an industrial air conditioner manufacturing company for designing sustainable supply chain: a fuzzy hybrid multi-criteria decision-making approach, in: Wireless Netw, 26 (2020) pp. 5759-5782.

[20] M. He, T. Lin, X. Wu, J. Luo, Y. Peng, A Systematic Literature Review of Reverse Logistics of End-ofLife Vehicles: Bibliometric Analysis and Research Trend, in: Energies, 13(21) (2020) pp. 5586.

[21] R. A. Foroutan, J. Rezaeian, I. Mahdavi, Green vehicle routing and scheduling problem with heterogeneous fleet including reverse logistics in the form of collecting returned goods, in: Applied Soft Computing, 94 (2020) pp. 106462.

[22] A. Morales-Plaza et al., Waste Management Model Based on Reverse Logistics and $5 \mathrm{~S}$ for the Generation of Biomass in the Fresh Fruit Industry, in: 2020 9th International Conference on Industrial Technology and Management (ICITM), Oxford, United Kingdom, 2020, pp. 11-15.

[23] M.J. Santos et al., The vehicle routing problem with backhauls towards a sustainability perspective: a review. TOP, 28 (2020) pp. 358-401.

[24] Y. Kuvvetli, R. Erol, Coordination of production planning and distribution in closed-loop supply chains, in: Neural Comput \& Applic, 32 (2020) pp. 13605-13623.

[25] M. Rabbani, et al., Incorporating location routing model and decision making techniques in industrial waste management: Application in the automotive industry, in: Computers \& Industrial Engineering, 148 (2020) 106692.

[26] R. Wei, C. Liu, Research on carbon emission reduction in road freight transportation sector based on regulation-compliant route optimization model and case study, in: Sustainable Computing: Informatics and Systems, 28 (2020) pp. 100408. 